\title{
Assessment of research waste part 2: wrong study populations- an exemplar of baseline vitamin $D$ status of participants in trials of vitamin D supplementation
}

Mark J. Bolland ${ }^{1 *}$ (D) Andrew Grey ${ }^{1}$ and Alison Avenell ${ }^{2}$

\begin{abstract}
Background: Research waste can occur when trials are conducted in the wrong populations. Vitamin D deficient populations are most likely to benefit from vitamin D supplementation. We investigated waste attributable to randomised controlled trials (RCTs) of supplementation in populations that were not vitamin D deficient.

Methods: In December 2015, we searched Pubmed, recent systematic reviews, and three trial registries for RCTs of vitamin D with clinical endpoints in adults, and 25-hydroxvitamin D (250HD) survey data relevant to large $(N \geq 1000) R C T s$. We investigated the proportion of RCTs that studied vitamin D deficient populations, temporal trends in baseline 25OHD, and whether investigators in large RCTs considered relevant 25OHD survey data or systematic reviews in their trial justifications.

Results: Of 137 RCTs of vitamin D with clinical endpoints, 118 (86\%) reported baseline mean/median 25OHD, which was $<25,25-49,50-74$, and $\geq 75 \mathrm{nmol} / \mathrm{L}$ in 12 (10\%), 62 (53\%), 36 (31\%), and 8 (7\%) RCTs, respectively. In 70\% of RCTs, baseline 25OHD was $>40 \mathrm{nmol} / \mathrm{L}$. Baseline 25OHD increased over time. Before 2006, 38\%, 62\%, $0 \%$ and $0 \%$ of RCTs had baseline $25 \mathrm{OHD}<25,25-49,50-74$, and $\geq 75 \mathrm{nmol} / \mathrm{L}$ respectively; in 2011-15, the respective proportions were 9\%, $49 \%, 37 \%$, and $6 \%$. Of 12 RCTs with baseline $25 \mathrm{OHD}<25 \mathrm{nmol} / \mathrm{L}$, 8 had neutral findings. Of 25 large RCTs (18 completed, 7 ongoing), 1 was undertaken in a vitamin D deficient population, 3 in vitamin D insufficient populations, and 17 had, or probably will have, baseline $25 \mathrm{OHD}>40 \mathrm{nmol} / \mathrm{L}$. 44\% (8/18) of large completed RCTs cited relevant prior population $25 \mathrm{OHD}$ data, and only 3/10 (30\%) relevant prior systematic reviews.
\end{abstract}

Conclusions: Up to $70 \%$ of RCTs of vitamin D with clinical endpoints, $71 \%$ of large completed RCTs, and 100\% of ongoing large RCTs could be considered research waste because they studied cohorts that were not vitamin $D$ deficient.

Keywords: Vitamin D, Deficiency, Sufficiency, Randomized controlled trials, Research waste, Fracture, Cardiovascular disease, Cancer, Mortality

\footnotetext{
* Correspondence: m.bolland@auckland.ac.nz

'Department of Medicine, Bone and Joint Research Group, University of

Auckland, Private Bag 92 019, Auckland 1142, New Zealand

Full list of author information is available at the end of the article
}

(c) The Author(s). 2018 Open Access This article is distributed under the terms of the Creative Commons Attribution 4.0 International License (http://creativecommons.org/licenses/by/4.0/), which permits unrestricted use, distribution, and reproduction in any medium, provided you give appropriate credit to the original author(s) and the source, provide a link to the Creative Commons license, and indicate if changes were made. The Creative Commons Public Domain Dedication waiver (http://creativecommons.org/publicdomain/zero/1.0/) applies to the data made available in this article, unless otherwise stated. 


\section{Background}

Chalmers and Glasziou estimated that $85 \%$ of clinical research is wasteful, with $50 \%$ of studies having design or major methodological weaknesses [1]. In these companion reports, we assessed research waste in a single field calcium and vitamin D research. In the first report [2], we focused on redundant research characterized by the undertaking and publication of uninformative observational studies and randomised controlled trials (RCTs) with surrogate endpoints long after the need for large RCTs with 'hard' clinical endpoints was established. In this second report, we address waste characterised by conducting RCTs in poorly targeted population groups.

Clinical guidelines disagree on the serum 25-hydroxyvitamin D (25OHD) concentrations that constitute vitamin D sufficiency. The Institute of Medicine recommends $\geq 50 \mathrm{nmol} / \mathrm{L}$ to ensure adequate 25OHD for $97.5 \%$ of the population, with a median target value of $40 \mathrm{nmol} / \mathrm{L}$ [3], whereas the Endocrine Society recommends $\geq 75 \mathrm{nmol} / \mathrm{L}$ [4]. However despite this disagreement, there is general agreement that 25OHD < $25 \mathrm{nmol} / \mathrm{L}$ indicates deficiency, and recent UK guidance on vitamin $\mathrm{D}$ supplementation is based on maintaining 25OHD above this threshold [5]. Mildly low 25OHD is often termed vitamin D insufficiency, and moderately low 25OHD vitamin D deficiency. Throughout the text, we have used vitamin D deficiency to refer to $25 \mathrm{OHD}<$ $25 \mathrm{nmol} / \mathrm{L}$, and insufficiency to $25 \mathrm{OHD}<50 \mathrm{nmol} / \mathrm{L}$ [6]. Intuitively, supplementing populations that are vitamin $\mathrm{D}$ deficient is more likely to produce benefits than supplementing populations with higher 25OHD [7]. Potential benefits of vitamin $\mathrm{D}$ could be obscured if a high proportion of participants in RCTs are vitamin D sufficient. Thus, RCTs in cohorts that are vitamin D sufficient are unlikely to show benefits of vitamin D supplementation and could be considered research waste. Recent systematic reviews of RCTs of vitamin D supplementation have not shown benefits on skeletal or non-skeletal endpoints [8-11]. We set out to determine what proportion of RCTs of vitamin D supplementation with clinical endpoints has been conducted in vitamin $\mathrm{D}$ deficient populations, and whether baseline 25OHD in such RCTs have changed over time. We then focused on large RCTs either already completed or in progress, identified data on target population vitamin D status available prior to the trial, and determined whether the investigators reported relevant data on vitamin D status. We also determined whether investigators reported relevant systematic reviews in their trial justification, as recommended $[1,12]$.

\section{Methods}

\section{Literature searches}

In December 2015, we searched Pubmed for RCTs of vitamin $\mathrm{D}$ in adults (>18y) (Additional file 1: Table S1) and for recent systematic reviews on clinical conditions and major surrogate endpoints that were the primary endpoints in identified RCTs (Additional file 1: Tables S2 and S3). We included trials with an untreated or placebo group, trials comparing different vitamin D doses, trials with or without calcium supplements, and trials with multiple interventions provided that 2 study arms differed only by the use of vitamin D. We included quasi-randomized trials but excluded trials where the method of allocation was sequential or unreported, trials where vitamin $\mathrm{D}$ was administered routinely post-thyroidectomy, and trials of hydroxylated vitamin D analogues. The flow of articles is shown in Additional file 1: Figure S1.

In December 2015, we also searched ClinicalTrials.gov (https://clinicaltrials.gov/), the International Standard Randomised Controlled Trial Number (ISRCTN) registry (http://www.isrctn.com/) and the Australian New Zealand Clinical Trials Registry (ANZCTR) (http:// www.anzctr.org.au/) for completed and ongoing trials, using vitamin $\mathrm{D}$ as the search term.

Finally, we obtained vitamin D status survey data from published systematic reviews [13-17]. supplemented by Medline, Embase, and Google searches using our vitamin D search strategy and text words for the countries of interest, and checked citations in reference lists.

\section{Trial classification}

We categorised each RCT according to whether clinical or surrogate endpoints were reported in the Abstract (or full-text where there was no Abstract), using the Institute of Medicine definition of surrogate outcomes as "biomarker[s] intended to substitute for a clinical endpoint [and] expected to predict clinical benefit (or harm. ..) based on epidemiologic, therapeutic, pathophysiologic, or other scientific evidence" [18]. Where multiple endpoints were reported, we recorded the most relevant clinical endpoint, and if there were no clinical endpoints, the most clinically relevant surrogate endpoint. Where there were multiple publications from the same RCT, we included the study with the most relevant clinical endpoint or the most clinically relevant surrogate endpoint.

\section{Vitamin D status survey data}

For large $(N \geq 1000)$ completed and ongoing RCTs, we identified surveys of vitamin D status undertaken in the same country and most similar population group, based on age and sex, prior to the trial being undertaken. We preferentially sought data from the five years before trial inception or 10 years before trial completion/publication, but used older data if we could not locate such data.

\section{Analyses}

A single author (MB or $\mathrm{AA}$ ) extracted relevant data. One author $(\mathrm{MB})$ classified trials as having clinical or 
surrogate endpoints, and a second author (AG) checked the classifications. We report the proportions of trials with mean/median baseline 25OHD < 25, 25-49, 50-74, $\geq 75 \mathrm{nmol} / \mathrm{L}$ over time. In trials with mean/median baseline $25 \mathrm{OHD}<25 \mathrm{nmol} / \mathrm{L}$ and trials that reported a subgroup analysis based on baseline 25OHD, two authors (MB, AG) independently assessed whether the results of the trial or subgroup analysis were beneficial, neutral, or harmful and disagreements were resolved by consensus.

We examined primary trial publications, and trial protocols (where available), for large RCTs $(N \geq 1000)$ and assessed whether trial investigators discussed prior relevant evidence on vitamin $\mathrm{D}$ status of the intended trial population in their justification for the trial. We also examined whether trial investigators discussed systematic reviews of randomised trials relevant to the primary endpoint that were available before trial recruitment commenced in the Introduction section of the primary publication.

Early 25OHD competitive binding protein (CBP) assays overestimated 25OHD concentrations [19]. As an approximation, we used an adjustment factor of 0.54 for CBP assays in papers published before 2000 [19]. and 0.76 to adjust for overestimation from the Nicholls' immunoassay [20]. We have presented the RCT and survey data in Tables 3 and 4 corrected for these overestimations.

\section{Results}

\section{Baseline 250HD in randomised controlled trials}

From 4682 unique Pubmed records and 38 systematic reviews, we identified 779 publications from 547 RCTs of vitamin D, of which 137 (111,976 participants) reported a clinical endpoint in the Abstract (Additional file 1: Tables S1, S2, S3 and Figure S1). Figure 1a shows that the rate of publication of RCTs has increased markedly, with 11 RCTs in 2001-5, 28 in 2006-10, and 88 in 2011-15. Mean/median baseline 25OHD was reported in 118/137 (86\%) RCTs (Fig. 1b), with 62\%, 82\%, and 93\% of RCTs reporting baseline 25OHD before 2006, in 2006-10, and in 2011-15 respectively. Overall, mean/ median baseline 25OHD was $<25,25-49,50-74$, and $\geq$ $75 \mathrm{nmol} / \mathrm{L}$ in 12 (10\%), 62 (53\%), 36 (31\%), and 8 (7\%)

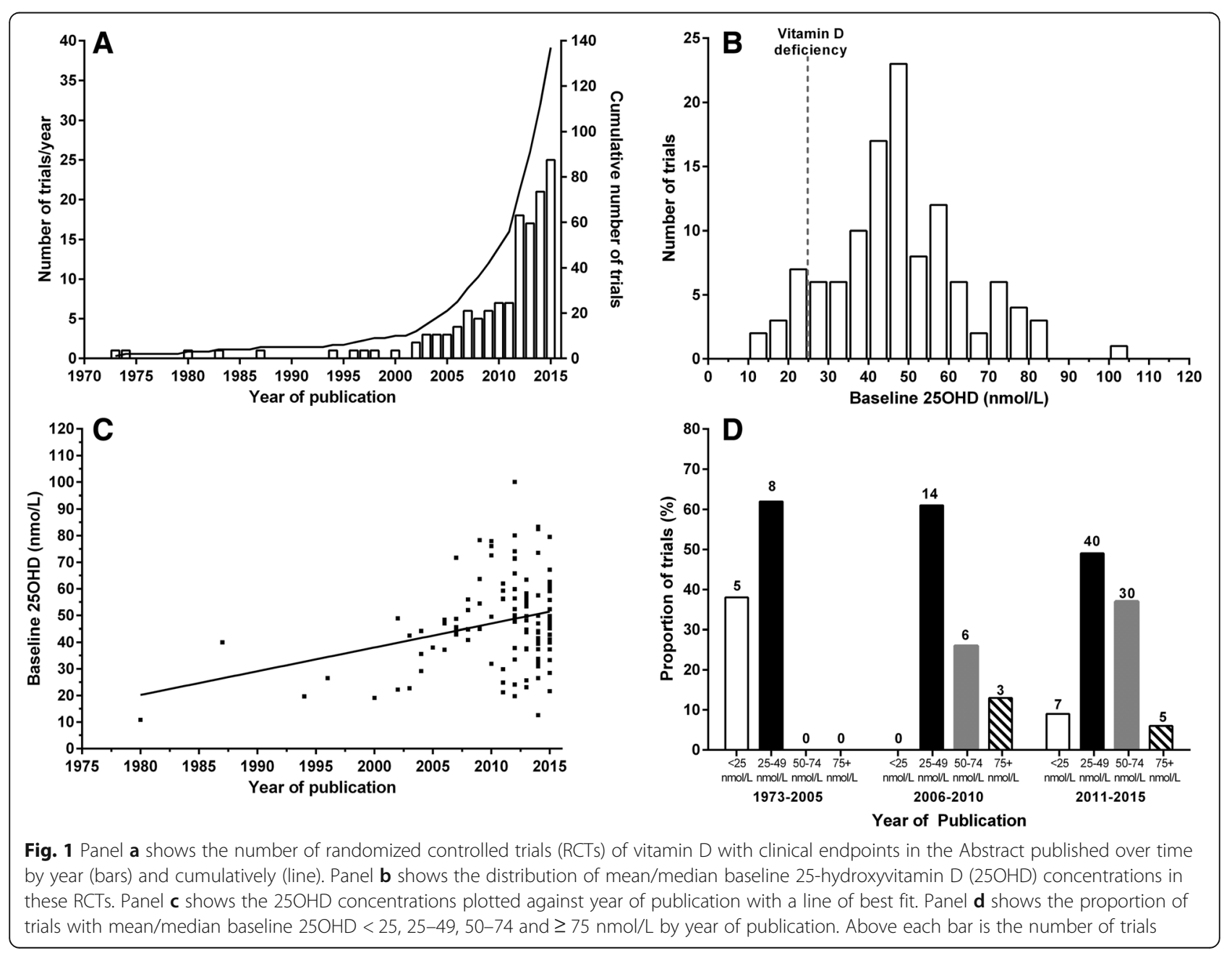


RCTs, respectively. In $70 \%$ of RCTs, baseline 25OHD was $>40 \mathrm{nmol} / \mathrm{L}$. Of $12 \mathrm{RCTs}$ with baseline $25 \mathrm{OHD}<$ $25 \mathrm{nmol} / \mathrm{L}, 8$ had neutral findings (Table 1).

Figure $1 \mathrm{c}$ and $\mathrm{d}$ show that mean/median baseline 25OHD has increased over time. Before 2006, 38\% of RCTs had $25 \mathrm{OHD}<25 \mathrm{nmol} / \mathrm{L}, 62 \%$ between 25 and $49 \mathrm{nmol} / \mathrm{L}$, and none $\geq 50 \mathrm{nmol} / \mathrm{L}$. In $2006-10$ and $2011-15,0 \%$ and $9 \%$ respectively of RCTs had $25 \mathrm{OHD}$ $<25 \mathrm{nmol} / \mathrm{L}$, while $61 \%$ and $49 \%$ respectively had 25OHD 25-49 nmol/L, $26 \%$ and $37 \%$ respectively had 25OHD $50-74 \mathrm{nmol} / \mathrm{L}$, and $13 \%$ and $6 \%$ respectively had $25 \mathrm{OHD} \geq 75 \mathrm{nmol} / \mathrm{L}$.

Of 118 RCTs that reported mean/median baseline 25OHD, 19 (16\%) reported a subgroup analysis for baseline 25OHD (Table 2). The 25OHD thresholds used in these analyses ranged from 20 to $80 \mathrm{nmol} / \mathrm{L}$, with 5 analyses based on thresholds $\leq 25 \mathrm{nmol} / \mathrm{L}$ and 16 on thresholds $\leq 50 \mathrm{nmol} / \mathrm{L}$. Table 2 shows that $17 \mathrm{RCTs}$ reported similar results in the subgroup analysis and the main analysis for the primary endpoint (16 both analyses neutral, and 1 both analyses showed benefit for vitamin D). Three of these 17 RCTs reported a benefit for vitamin D for a secondary endpoint in a subgroup analysis. Another RCT did not report the result of the subgroup analysis for the primary endpoint, but reported a benefit for vitamin D for a secondary endpoint. Lastly, one RCT had co-primary endpoints and neutral results in the main analyses, but in the subgroup analyses there was a benefit for vitamin $\mathrm{D}$ for one endpoint and neutral results for the other. Four of the five RCTs that reported subgroup analyses with a 25OHD threshold of $\leq 25 \mathrm{nmol} / \mathrm{L}$ had neutral results for the primary endpoint in the main analysis, and none of these 4 RCTs reported beneficial effects for the primary endpoint in the subgroup analysis.

\section{Large randomised controlled trials and prior 250HD surveys}

Tables 3 and 4 show 18 published RCTs of vitamin D with $\geq 1000$ participants (101,383 participants), and 7 planned and ongoing trials (79,939 intended participants). We included the pilot stage for the UK VIDAL trial with 1600 participants, which aimed to continue and recruit 20,000 participants, but has not yet received funding for the full roll out. All trials were/are conducted exclusively in North America, Europe, Australia or New Zealand, except for two multinational trials with countries from South America, Asia and Africa. 22/25 trials were in single countries: we did not examine prior 25OHD surveys for the 3 multinational trials.

Table 3 shows that only 8 [21-28] of the 18 completed trials $(44 \%)$ cited the vitamin D status of a population similar to the recruited cohort in the primary publication. One further trial [29] discussed survey data in the trial paper's introduction, but this was not used in the grant application. Investigators from two of these trials $[21,22]$ had undertaken prior relevant 25OHD surveys. Four of the eight trials cited old survey data, from at least 16 years $[24,27]$ and $6-9$ years $[23,26]$ before trial recruitment. A trial from Finland that studied older

Table 1 Characteristics of 12 randomised controlled trials of vitamin D supplements in populations with mean/median $250 \mathrm{HD}<25 \mathrm{nmol} /$ $\mathrm{L}$ and clinical endpoints reported in abstract

\begin{tabular}{|c|c|c|c|c|c|c|}
\hline Study & Clinical endpoint & Endpoint type & Study Size (N) & 25OHD Assay & $\begin{array}{l}\text { Mean/Median } \\
25 \mathrm{OHD}(\mathrm{SD})(\mathrm{nmol} / \mathrm{L})^{\mathrm{a}}\end{array}$ & Result of Trial $^{b}$ \\
\hline Brooke 1980 [44] & Newborn outcomes & Secondary & 126 & CBP & $11(1)$ & Benefit \\
\hline Chapuy 1994 [21] & Fracture & Primary & 3270 & CBP & $20(14)$ & Benefit \\
\hline Pfeifer 2000 [45] & Risk of fall & Secondary & 148 & Nicholls & $19(10)$ & Neutral \\
\hline Chapuy 2002 [46] & Fracture & Secondary & 583 & Incstar & $22(16)$ & Neutral \\
\hline Bischoff 2003 [47] & Risk of fall & Primary & 122 & Nicholls & $23(\mathrm{~N} / \mathrm{A})$ & Neutral \\
\hline Martineau 2011 [48] & $\begin{array}{l}\text { Tuberculosis sputum } \\
\text { culture conversion }\end{array}$ & Primary & 126 & LCMS/MS & $21(20)$ & Neutral \\
\hline Mosayebi 2011 [49] & $\begin{array}{l}\text { Multiple sclerosis } \\
\text { disability score }\end{array}$ & Primary & 59 & IDS & $25(7)$ & Neutral \\
\hline Amestejani 2012 [50] & Atopic dermatitis & Primary & 60 & Biosource & $24(5)$ & Benefit \\
\hline Schreuder 2012 [51] & Pain & Primary & 84 & Diasorin & $20(10)$ & Neutral \\
\hline Mozaffari-Khosravi 2013 [52] & Depression score & Primary & 120 & IDS & $23(\mathrm{~N} / \mathrm{A})$ & Benefit \\
\hline Hossain 2014 [53] & Pregnancy outcomes & Primary & 200 & Immunoassay & $13(\mathrm{~N} / \mathrm{A})$ & Neutral \\
\hline Bhan 2015 [54] & All-cause mortality & Secondary & 105 & LCMS/MS & $22(7)$ & Neutral \\
\hline
\end{tabular}

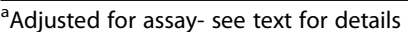

${ }^{b}$ Based on intention-to-treat analysis of all randomized participants for relevant endpoint. Assessed independently by two authors (MB, AG)

Studies are listed in Additional file 1: Table S3 and the Additional file 1: Reference list

Abbreviations: $250 H D$ 25-hydroxyvitamin D, SD standard deviation, N/A not available. CBP competitive binding protein; LCMS/MS- liquid chromatography

tandem mass-spectrometry 
Table 2 Results of 18 randomised controlled trials of vitamin D supplements reporting subgroup analyses for baseline 25hydroxyvitamin D

\begin{tabular}{llll}
\hline Study & 25OHD threshold (nmol/L) & Subgroup Result $^{\text {a }}$ & Comparison to primary analysis $^{\text {a }}$ \\
\hline Jackson 2006 [33] & 32.2 & Neutral & Same \\
Jorde 2008 [55] & 40 & NR & N/A $^{\text {b }}$ \\
Wejse 2009 [56] & 75 & Neutral & Same \\
Martineau 2011 [48] & 20 & Neutral & Same \\
Rastelli 2011 [57] & 50 & Neutral & Same $^{c}$ \\
Kjaergaard 2012 [58] & 25 & Neutral & Same \\
Lehouck 2012 [59] & 25 & Neutral & Same \\
Murdoch 2012 [60] & 50 & Neutral & Same \\
Abou-Raya 2013 [61] & 25 & Benefit & Same \\
McAlindon 2013 [62] & 37.5 & Neutral & Same \\
Amrein 2014 [63] & 30 & Neutral & Same \\
Lopez-Torres Hidalgo 2014 [64] & 80 & Neutral & Same \\
Tran 2014 [65] & 50 & Neutral & Same \\
Turner 2014 [66] & 50 & Neutral & Same \\
Baron 2015 [36] & 57.9 & Neutral & Same \\
Martineau 2015 [67] & 50 & Benefit & Different \\
Miskulin 2015 [68] & 37.5 & Neutral & Same \\
Sandoughi 2015 [69] & 50 & Neutral & Neutral \\
Tukvadze 2015 [70] & 25 & Same
\end{tabular}

${ }^{a}$ Assessed independently by two authors (MB, AG)

b Benefit for secondary endpoint in subgroup analysis

c Primary endpoint not specified. Benefits in subgroup analyses for some but not all reported endpoints

d Two co-primary endpoints. Benefit in subgroup analysis for one co-primary endpoints. For other co-primary endpoint, subgroup analysis was neutral. In primary analyses, results for both co-primary endpoints were neutral

Studies are listed in Additional file 1: Table S3 and Reference list

Abbreviations: 25OHD 25-hydroxyvitamin D, NR not reported; N/A not applicable

adults (mean age 62y) cited survey data that lacked relevance, being from the USA and from young Finnish adults (mean age 38y) [30].

Table 4 shows that all four ongoing trials with accessible documents discuss the vitamin D status of their intended trial population. One trial in Australia conducted a pilot study that included assessment of vitamin D status. The US VITAL trial which started recruitment in 2010, used NHANES III (1988-94) data in its rationale and design paper justification [31, 32].

Table 3 shows that baseline 25OHD in large completed RCTs and relevant survey 25OHD data were comparable, apart from one Norwegian trial, where one survey indicated considerably worse vitamin D status than was observed in trial participants [23]. Only one [21] of the completed trials was conducted in a population that was clearly vitamin $\mathrm{D}$ deficient, based on trial (mean baseline 25OHD $20 \mathrm{nmol} / \mathrm{L}$ ) and survey data (mean 11-23 nmol/L). Three trials [22, 24, 29] were undertaken in populations comprised largely of participants with vitamin D insufficiency. Of the remaining 13 single country trials with baseline 25OHD or relevant survey data, five trials [23, 27, 33-35] had mean baseline
$25 \mathrm{OHD} \geq 40 \mathrm{nmol} / \mathrm{L}$ and four trials $25 \mathrm{OHD} \geq 50 \mathrm{nmol} / \mathrm{L}$ [26, 28, 30, 36]. Four trials [25, 37-39] did not report baseline 25OHD, but surveys and data from similar RCTs suggest that baseline 25OHD in the RCT would have been $\geq 40 \mathrm{nmol} / \mathrm{L}$ in three of these trials $[25,37$, 38 ]. In these 13 trials, a substantial proportion of participants would have had $25 \mathrm{OHD} \geq 50 \mathrm{nmol} / \mathrm{L}$, consistent with the IOM definition of vitamin D sufficiency [3].

Table 4 shows that, based on survey data from the relevant population, all the ongoing single country trials are likely to recruit participants in whom the mean/median baseline $25 \mathrm{OHD}$ will be $>40-50 \mathrm{nmol} / \mathrm{L}$, and none describe specific strategies for recruiting participants with $25 \mathrm{OHD}<25 \mathrm{nmol} / \mathrm{L}$.

\section{Large randomised controlled trials and citation of prior systematic reviews of randomised controlled trials}

We identified a relevant systematic review on vitamin D and fracture [40] published prior to trial recruitment starting for 8 completed large RCTs, and on mortality [41] for 2 RCTs, but no prior systematic reviews on colorectal adenoma or neonatal bone mineral content for two RCTs (Table 3). Thus, systematic reviews capable 


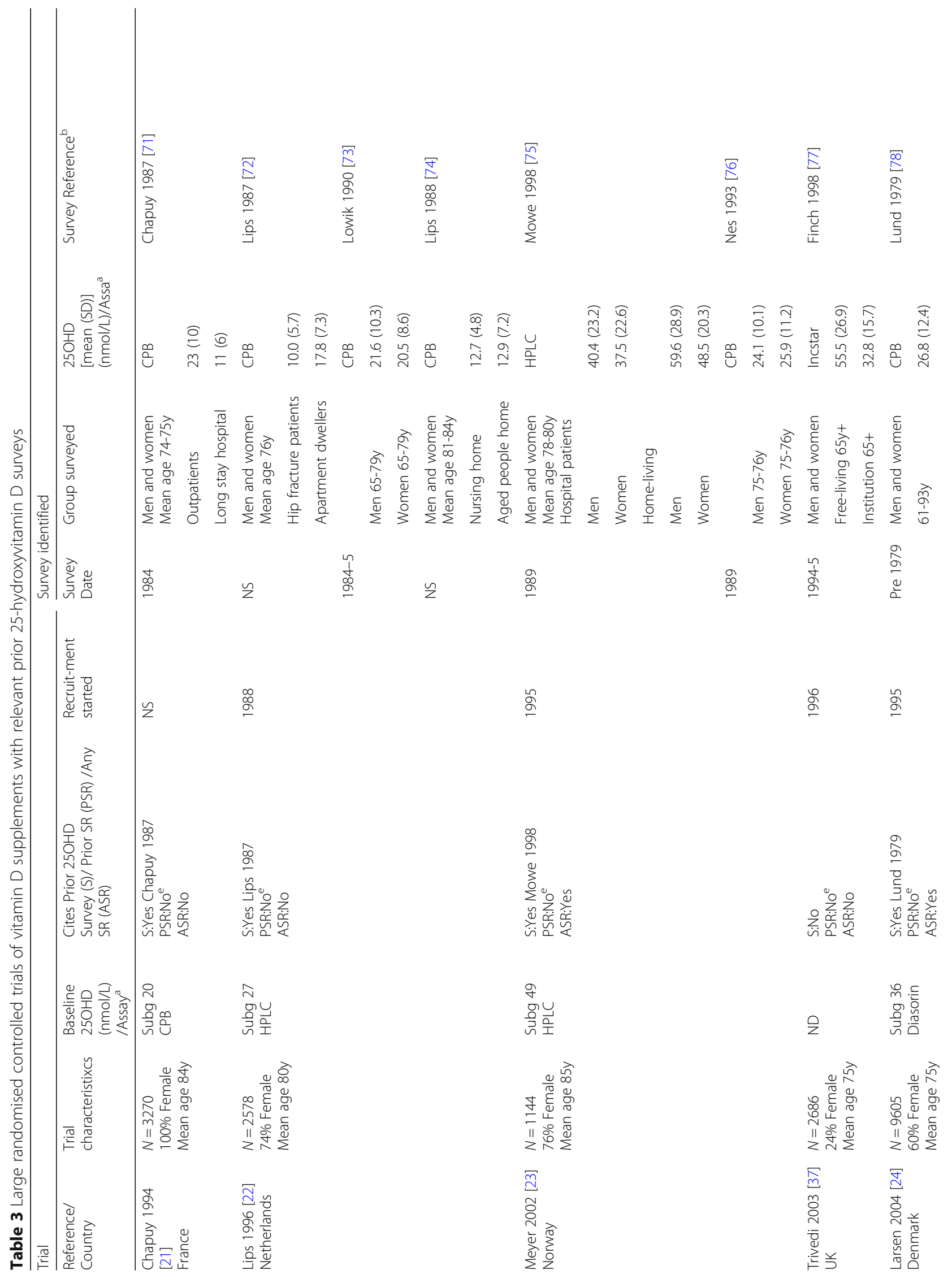




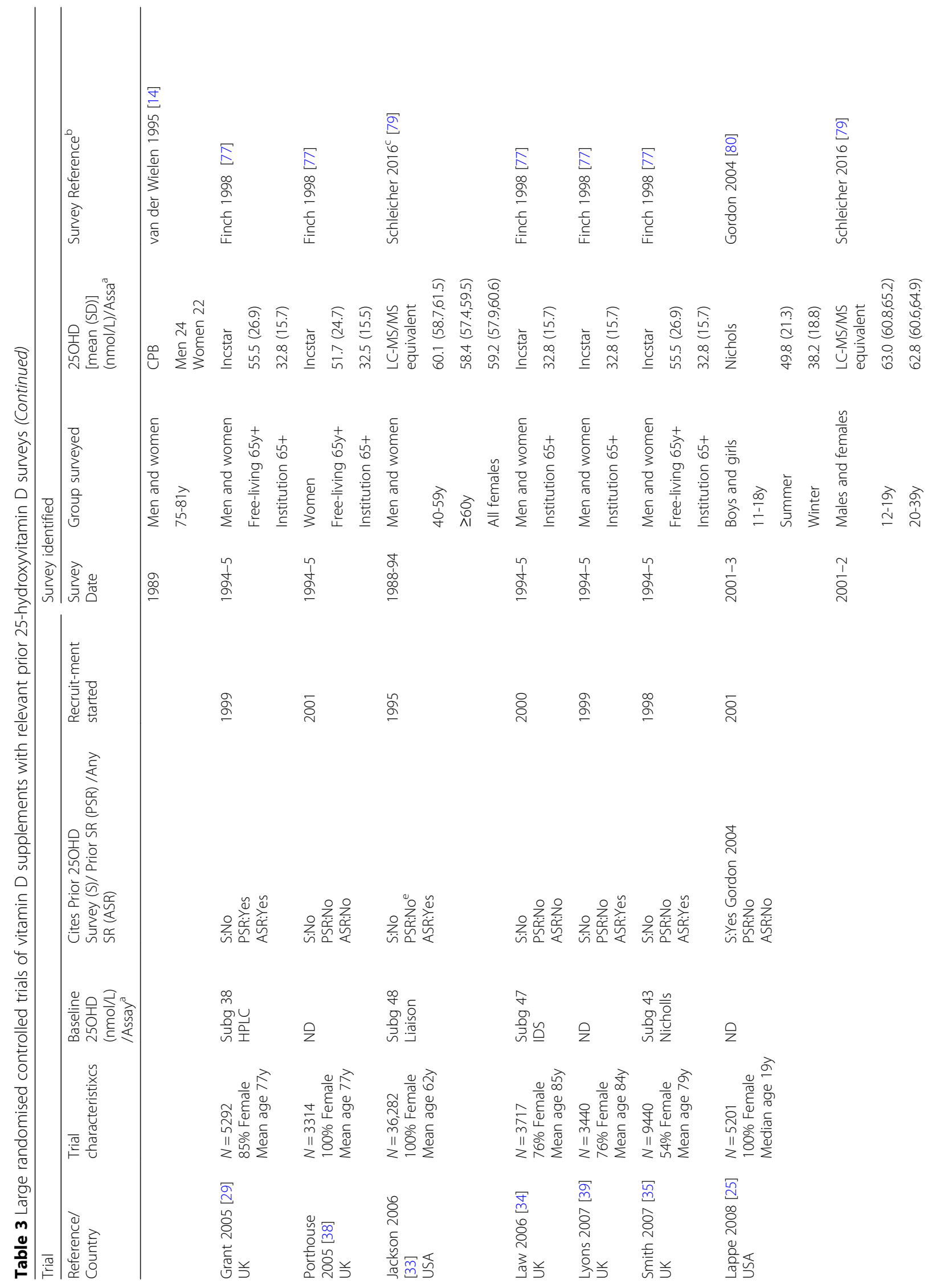




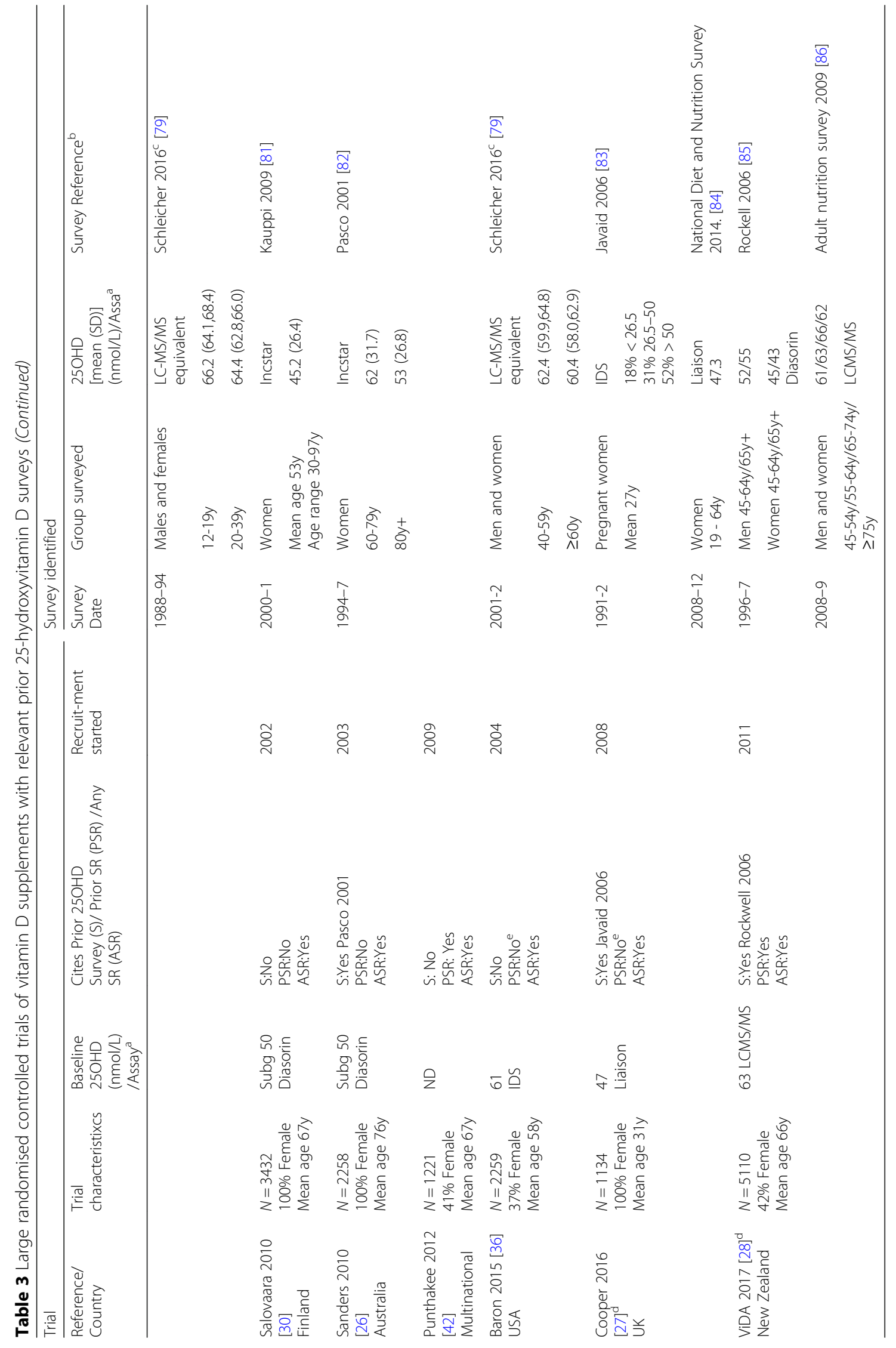




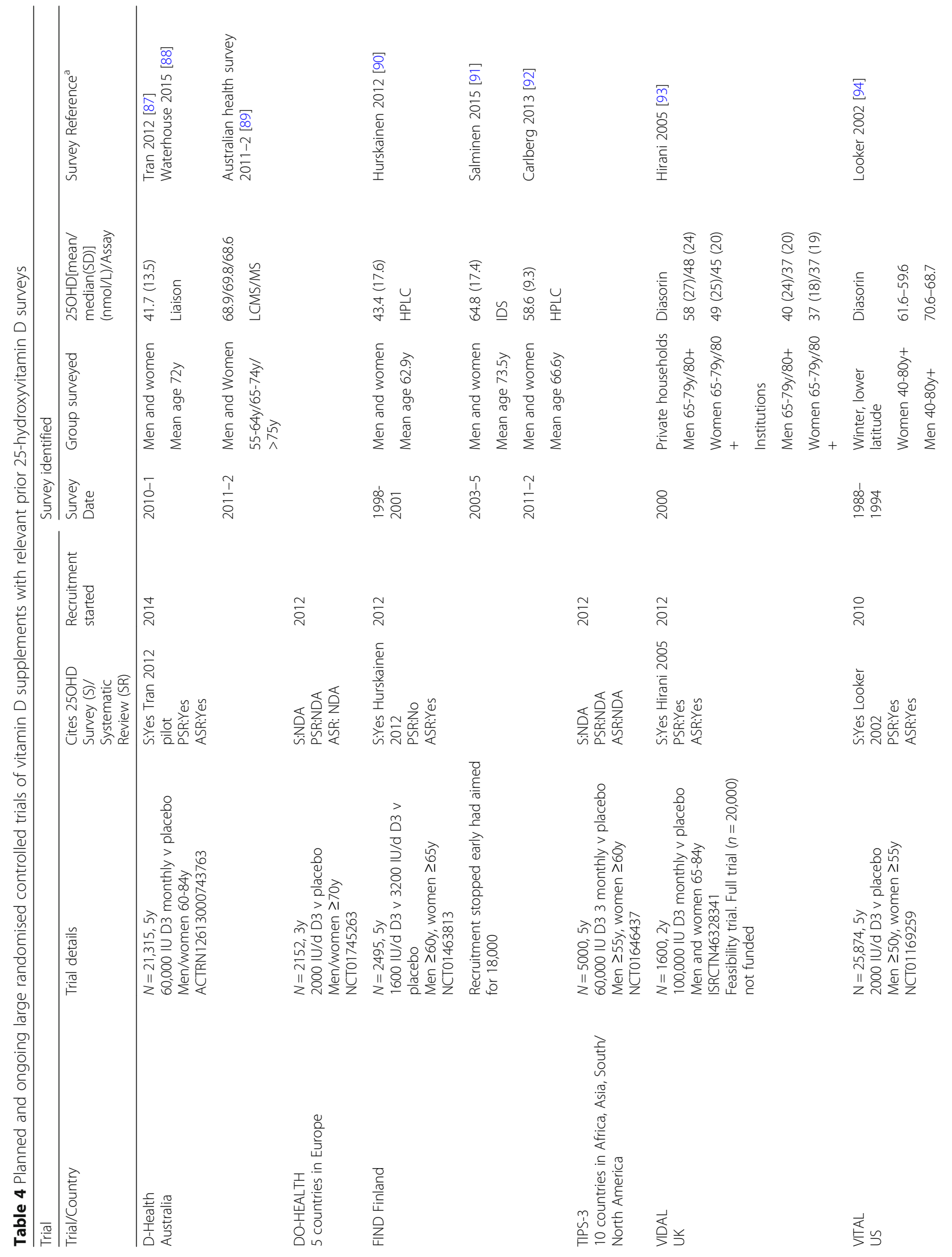




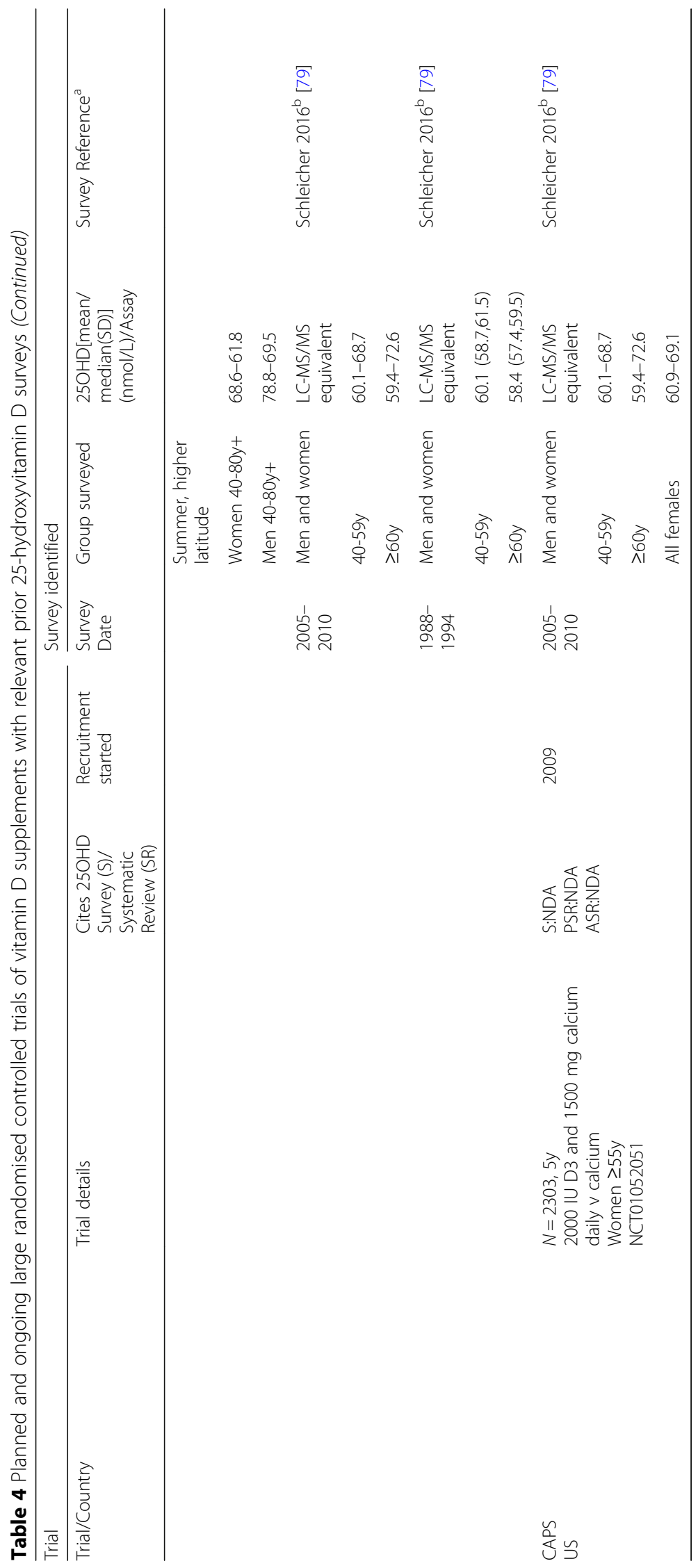


of informing the trial justification and design were available before trial recruitment in 10/18 (56\%) of completed large RCTs. Only three [28, 29, 42] of the 10 RCTs (30\%) cited such a systematic review in their primary publication. Nine trials $(50 \%)$ cited systematic reviews that would have occurred after the decision had been made to undertake the trial. Four of the seven planned or ongoing trials with accessible relevant documents discuss systematic reviews in their protocols or publications: for three of the trials, the systematic reviews predate trial recruitment.

\section{Discussion}

Our results suggest a high proportion of research waste in RCTs of vitamin D supplementation. The recent proliferation of vitamin D RCTs was accompanied by increasing baseline 25OHD concentrations and therefore a declining proportion of RCTs conducted in vitamin D deficient cohorts. Only $10 \%$ of trials were carried out in populations that would be widely accepted as vitamin $\mathrm{D}$ deficient, in which benefits of vitamin D supplementation still have not been unequivocally established (Table 1 ). Because many participants in recent trials were vitamin D sufficient, they would be unlikely to benefit from vitamin D. Further, their inclusion could have obscured potential benefits from vitamin $D$ for those participants who were vitamin $\mathrm{D}$ deficient. This issue applies to RCTs with mean/median baseline 25OHD in ranges variously defined as sufficient $(7 \%$ with $25 \mathrm{OHD}$ $\geq 75 \mathrm{nmol} / \mathrm{L}, 37 \%$ with $25 \mathrm{OHD} \geq 50 \mathrm{nmol} / \mathrm{L}$ ). It likely also applies to the $33 \%$ of trials with baseline $25 \mathrm{OHD}$ $40-49 \mathrm{nmol} / \mathrm{L}$ in which a substantial proportion of participants will have had $25 \mathrm{OHD} \geq 50 \mathrm{nmol} / \mathrm{L}$. Thus, 7$37 \%$ of trials can be considered research waste, because they were conducted in the wrong population, but this proportion is as high as $70 \%$ if a $25 \mathrm{OHD}$ threshold for sufficiency of $40 \mathrm{nmol} / \mathrm{L}$ was applied, based on the Institute of Medicine's target median value.

Very importantly, research waste was prevalent in large RCTs that were designed to inform clinical practice. Only 1 such trial was carried out in a vitamin D deficient population and another 3 in populations with vitamin D insufficiency. Twelve (71\%) of the remaining completed and $5(100 \%)$ ongoing single country trials had, or are likely to have, mean baseline 25OHD > $40 \mathrm{nmol} / \mathrm{L}$, and based on survey and other trial data, we estimate that about $50 \%$ would have $25 \mathrm{OHD} \geq 50 \mathrm{nmol} /$ L. Failure to incorporate key available data during protocol development may have contributed to the high prevalence of waste. Few (44\%) of the large completed RCTs cited or undertook prior relevant surveys of vitamin D status in their intended trial population. Only $56 \%$ of large completed RCTs had a relevant systematic review of randomised trials published prior to trial recruitment starting and, of these, only $30 \%$ cited such a review. When systematic reviews of randomised trials were discussed, they tended to have been published after the trial had commenced or been completed. Collectively, this suggests that these large, costly RCTs were not optimally designed to address the question of benefits of vitamin D supplements.

An important strength of this study assessing research waste is that we analysed the complete set of RCTs of vitamin D published over 30 years. The results from this single research area might not apply to other research fields, and waste may be more prevalent in mature as opposed to emerging areas of research. In assessing whether trials cited 25OHD surveys or relevant systematic reviews, we examined primary publications and protocols where available. Our results may have changed if we were able to examine grant applications and trial protocols, but protocols were often not available, and we had access to only one grant application [29]. Early 25OHD assays tended to overestimate 25OHD- we used 25OHD concentrations corrected for these overestimates. The corrected values are approximations, but nevertheless lower than the original values in the relevant trials and surveys, and therefore the proportions of participants with vitamin D deficiency in our analyses are higher than in the original publications. Very few RCTs reported the season when $25 \mathrm{OHD}$ measurements were obtained. Although seasonal changes in 25OHD will occur in all treatment arms, it is possible that seasonal effects of 25OHD might confound some trial results. A limitation of this study is that the literature search was conducted in December 2015.

The implications of this research are that the current body of RCTs of vitamin D with clinical endpoints, including large RCTs with $\geq 1000$ participants, is largely conducted in populations that are not vitamin D deficient. Recent, large systematic reviews of these RCTs report no benefits of vitamin D [8-11]. In trials included in these meta-analyses reporting $25 \mathrm{OHD}, 72-75 \%$ had baseline $25 \mathrm{OHD}<50 \mathrm{nmol} / \mathrm{L}[10,43]$, consistent with Fig. 1d showing that the majority of trials prior to 2011 had baseline $25 \mathrm{OHD}<50 \mathrm{nmol} / \mathrm{L}$. Thus, it is reasonable to conclude that current evidence is sufficient to exclude benefits from vitamin $\mathrm{D}$ supplementation for unselected community-dwelling individuals with 25OHD >30$40 \mathrm{nmol} / \mathrm{L}$. Relatively few trials, including only 5003 participants (Table 1), have been carried out in populations with lower baseline 25OHD and their results are inconsistent, with only $33 \%$ of such trials reporting beneficial results from vitamin D. Subgroup analyses of participants with lower 25OHD at baseline were frequently undertaken but their results were invariably similar to the results of the main analyses for the primary endpoint, even when the subgroup was restricted to people 
with $25 \mathrm{OHD} \leq 25 \mathrm{nmol} / \mathrm{L}$. Therefore, it is uncertain whether vitamin $\mathrm{D}$ supplementation benefits people with clearly low 25OHD. Based on data from relevant 25OHD surveys, the large RCTs currently underway will not test the effects of vitamin D supplementation in deficient populations and therefore are unlikely to address this knowledge gap. Instead of continuing to spend resources on trials in vitamin D sufficient populations, investigators should focus on vitamin D deficient populations. Food fortification policies $[15,16]$, together with independent action by food manufacturers and new advice on supplementation [5], make it even less likely that future trials in deficient populations will be possible.

Our analyses suggest that up to $70 \%$ of RCTs with clinical endpoints, $71 \%$ of large $(N \geq 1000)$ completed RCTs, and $100 \%$ of ongoing large RCTs could be considered research waste because they studied cohorts with a high proportion of vitamin D sufficiency. In our companion paper [2], we reported that $69 \%$ of RCTs of vitamin D conducted since 2005 with skeletal endpoints of bone mineral density or fracture were research waste because they lacked novelty or did not add to existing clinical knowledge. Taken together, these findings support the very high proportions (> 85\%) for research waste estimated by Chalmers and Glasziou [1].

\section{Conclusions}

We identified a very high proportion of research waste in RCTs of vitamin D with clinical endpoints. Few RCTs were carried out in vitamin D deficient populations most likely to benefit from vitamin D supplementation, and conversely most RCTs were carried out in populations unlikely to benefit from supplementation. Few large RCTs appeared to consider systematic reviews in their design. Ongoing large RCTs share the same weaknesses of previous trials. Strategies to improve the design of RCTs should be introduced and studied to determine whether they can reduce research waste.

\section{Additional file}

Additional file 1: Table S1. Searches of Pubmed undertaken in December 2015. Table S2. 38 Systematic reviews identified in Pubmed search. Table S3. Characteristics of 137 randomised controlled trials of vitamin D supplements with clinical endpoints reported in abstract. Table S4. Large completed randomised controlled trials of vitamin D supplements with relevant prior 25-hydroxyvitamin D surveys. Table S5. Large ongoing randomised controlled trials of vitamin D supplements with relevant prior 25-hydroxyvitamin D surveys. Figure S1. flow of studies. References. (DOCX 313 kb)

\section{Abbreviations}

25OHD: 25-hydroxyvitamin D; CBP: Competitive binding protein; RCT: Randomised controlled trial

\section{Acknowledgements}

We thank the following for providing further information about their trial or survey: Paul Atyeo, Australian Bureau of Statistics, Australia; Anne Looker, Centers for Disease Control and Prevention, USA; Briony Romero and Rachel Neale, Queensland Institute of Medical Research, Berghofer Medical Research Institute, Australia. We also thank David Cooper, HSRU, University of Aberdeen, UK, for statistical advice; Shaun Treweek, HSRU, and Hilde Stromme, Norwegian Knowledge Centre for the Health Services, Oslo, for help locating a Norwegian publication.

\section{Funding}

No specific funding was received for this study. MB receives salary support from the Health Research Council of New Zealand. The Health Services Research Unit is funded by the Chief Scientist Office of the Scottish Government Health and Social Care Directorates. The funders had no role in the study design; collection, analysis, and interpretation of the data; writing of the report; and in the decision to submit the paper for publication.

\section{Availability of data and materials}

All data generated or analysed during this study are included in this published article and its supplementary information file.

\section{Authors' contributions}

$M B, A G$ and $A A$ designed the research. $M B$ and $A A$ performed the literature searches and extracted the data. MB, AA and AG reviewed the studies. MB and AA performed the analyses. MB drafted the paper. All authors critically reviewed and improved it. All authors read and approved the final manuscript.

Ethics approval and consent to participate

Not applicable.

\section{Consent for publication}

Not applicable.

\section{Competing interests}

$\mathrm{MB}, \mathrm{AG}$, and $\mathrm{AA}$ have all published randomised controlled trials and systematic reviews in the fields of calcium and vitamin $D$ but otherwise have no competing interests to declare.

\section{Publisher's Note}

Springer Nature remains neutral with regard to jurisdictional claims in published maps and institutional affiliations.

\section{Author details}

${ }^{1}$ Department of Medicine, Bone and Joint Research Group, University of Auckland, Private Bag 92 019, Auckland 1142, New Zealand. ${ }^{2}$ Health Services Research Unit, University of Aberdeen, Foresterhill, Aberdeen AB25 2ZD, Scotland.

Received: 3 December 2017 Accepted: 10 September 2018

Published online: 03 October 2018

\section{References}

1. Chalmers I, Glasziou P. Avoidable waste in the production and reporting of research evidence. Lancet. 2009;374:86-9.

2. Bolland MJ, Avenell A, Grey A. Assessment of research waste part 1: an exemplar from examining study design, surrogate and clinical endpoints in studies of calcium intake and vitamin D supplementation. BMC Med Res Methodol. https://doi.org/10.1186/s12874-018-0556-0

3. IOM (Institute of Medicine). Dietary reference intakes for calcium and vitamin D. Washington, DC: The National Academies Press; 2011.

4. Holick MF, Binkley NC, Bischoff-Ferrari HA, Gordon CM, Hanley DA, Heaney $\mathrm{RP}$, et al. Evaluation, treatment, and prevention of vitamin D deficiency: an Endocrine Society clinical practice guideline. J Clin Endocrinol Metab. 2011; 96:1911-30.

5. Scientific Advisory Committee on Nutrition (SACN). Vitamin D and Health. 2016:Available on line at https://www.gov.uk/government/uploads/system/ uploads/attachment_data/file/537616/SACN_Vitamin_D_and_Health_report. pdf (Accessed 25 July 2016). 
6. Lips P. Vitamin D deficiency and secondary hyperparathyroidism in the elderly: consequences for bone loss and fractures and therapeutic implications. Endocr Rev. 2001;22:477-501.

7. Heaney RP. Guidelines for optimizing design and analysis of clinical studies of nutrient effects. Nutr Rev. 2014;72:48-54.

8. Autier P, Boniol M, Pizot C, Mullie P. Vitamin D status and ill health: a systematic review. Lancet Diabetes Endocrinol. 2014;2:76-89.

9. Avenell A, Mak JC, O'Connell D. Vitamin D and vitamin D analogues for preventing fractures in post-menopausal women and older men. Cochrane Database Syst Rev. 2014;4:CD000227.

10. Bolland MJ, Grey A, Gamble GD, Reid IR. The effect of vitamin D supplementation on skeletal, vascular, or cancer outcomes: a trial sequential meta-analysis. Lancet Diabetes Endocrinol. 2014;2:307-20.

11. Theodoratou E, Tzoulaki I, Zgaga L, loannidis JP. Vitamin D and multiple health outcomes: umbrella review of systematic reviews and meta-analyses of observational studies and randomised trials. BMJ. 2014;348:92035.

12. Lund $H$, Brunnhuber $K$, Juhl $C$, Robinson $K$, Leenaars M, Dorch BF, et al. Towards evidence based research. BMJ. 2016;355:15440.

13. McKenna MJ. Differences in vitamin D status between countries in young adults and the elderly. Am J Med. 1992;93:69-77.

14. van der Wielen RP, Lowik MR, van den Berg H, de Groot LC, Haller J, Moreiras $\mathrm{O}$, et al. Serum vitamin D concentrations among elderly people in Europe. Lancet. 1995:346:207-10.

15. Hilger J, Friedel A, Herr R, Rausch T, Roos F, Wahl DA, et al. A systematic review of vitamin D status in populations worldwide. Br J Nutr. 2014;111:23-45.

16. Spiro A, Buttriss JL. Vitamin D: an overview of vitamin D status and intake in Europe. Nutr Bull. 2014;39:322-50.

17. Cashman KD, Dowling KG, Skrabakova Z, Gonzalez-Gross M, Valtuena J, De Henauw S, et al. Vitamin D deficiency in Europe: pandemic? Am J Clin Nutr. 2016;103:1033-44

18. IOM (Institute of Medicine). Evaluation of biomarkers and surrogate endpoints in chronic disease. Washington (DC): National Academies Press (US); 2010.

19. Lips P, Chapuy MC, Dawson-Hughes B, Pols HA, Holick MF. An international comparison of serum 25-hydroxyvitamin D measurements. Osteoporos Int. 1999:9:394-7.

20. Carter GD, Carter R, Jones J, Berry J. How accurate are assays for 25hydroxyvitamin D? Data from the international vitamin D external quality assessment scheme. Clin Chem. 2004;50:2195-7.

21. Chapuy MC, Arlot ME, Delmas PD, Meunier PJ. Effect of calcium and cholecalciferol treatment for three years on hip fractures in elderly women. BMJ. 1994;308:1081-2

22. Lips P, Graafmans WC, Ooms ME, Bezemer PD, Bouter LM. Vitamin D supplementation and fracture incidence in elderly persons. A randomized, placebo-controlled clinical trial. Ann Intern Med. 1996;124:400-6.

23. Meyer HE, Smedshaug GB, Kvaavik E, Falch JA, Tverdal A, Pedersen Jl. Can vitamin $D$ supplementation reduce the risk of fracture in the elderly? A randomized controlled trial. J Bone Miner Res. 2002;17:709-15.

24. Larsen ER, Mosekilde L, Foldspang A. Vitamin D and calcium supplementation prevents osteoporotic fractures in elderly community dwelling residents: a pragmatic population-based 3-year intervention study. J Bone Miner Res. 2004;19:370-8.

25. Lappe J, Cullen D, Haynatzki G, Recker R, Ahlf R, Thompson K. Calcium and vitamin d supplementation decreases incidence of stress fractures in female navy recruits. J Bone Miner Res. 2008;23:741-9.

26. Sanders KM, Stuart AL, Williamson EJ, Simpson JA, Kotowicz MA, Young D, et al. Annual high-dose oral vitamin D and falls and fractures in older women: a randomized controlled trial. JAMA. 2010;303:1815-22.

27. Cooper C, Harvey NC, Bishop NJ, Kennedy S, Papageorghiou AT, Schoenmakers I, et al. Maternal gestational vitamin D supplementation and offspring bone health (MAVIDOS): a multicentre, double-blind, randomised placebo-controlled trial. Lancet Diabetes Endocrinol. 2016:4:393-402.

28. Scragg R, Stewart AW, Waayer D, Lawes CMM, Toop L, Sluyter J, et al. Effect of monthly high-dose vitamin D supplementation on cardiovascular disease in the vitamin D assessment study a Randomized Clinical Trial. JAMA Cardiol. 2017:2:608-16.

29. Grant AM, Avenell A, Campbell MK, McDonald AM, MacLennan GS, McPherson GC, et al. Oral vitamin D3 and calcium for secondary prevention of low-trauma fractures in elderly people (randomised evaluation of calcium or vitamin D, RECORD): a randomised placebo-controlled trial. Lancet. 2005: 365:1621-8.
30. Salovaara K, Tuppurainen M, Karkkainen M, Rikkonen T, Sandini L, Sirola J, et al. Effect of vitamin D(3) and calcium on fracture risk in 65- to 71-year-old women: a population-based 3-year randomized, controlled trial--the OSTPRE-FPS. J Bone Miner Res. 2010;25:1487-95.

31. Manson JE, Bassuk SS, Lee IM, Cook NR, Albert MA, Gordon D, et al. The VITamin D and OmegA-3 TriaL (VITAL): rationale and design of a large randomized controlled trial of vitamin $\mathrm{D}$ and marine omega-3 fatty acid supplements for the primary prevention of cancer and cardiovascular disease. Contemp Clin Trials. 2012;33:159-71.

32. Bassuk SS, Manson JE, Lee IM, Cook NR, Christen WG, Bubes VY, et al. Baseline characteristics of participants in the VITamin D and OmegA-3 TriaL (VITAL). Contemp Clin Trials. 2016;47:235-43.

33. Jackson RD, LaCroix AZ, Gass M, et al. Calcium plus vitamin D supplementation and the risk of fractures. N Engl J Med. 2006;354(7):669-83.

34. Law M, Withers $\mathrm{H}$, Morris J, Anderson F. Vitamin D supplementation and the prevention of fractures and falls: results of a randomised trial in elderly people in residential accommodation. Age Ageing. 2006:35:482-6.

35. Smith H, Anderson F, Raphael H, Maslin P, Crozier S, Cooper C. Effect of annual intramuscular vitamin $\mathrm{D}$ on fracture risk in elderly men and women--a population-based, randomized, double-blind, placebo-controlled trial. Rheumatology (Oxford). 2007:46:1852-7.

36. Baron JA, Barry EL, Mott LA, et al. A Trial of Calcium and Vitamin D for the Prevention of Colorectal Adenomas. N Engl J Med. 2015;373(16):1519-30.

37. Trivedi DP, Doll R, Khaw KT. Effect of four monthly oral vitamin D3 (cholecalciferol) supplementation on fractures and mortality in men and women living in the community: randomised double blind controlled trial. BMJ. 2003:326:469.

38. Porthouse J, Cockayne S, King C, Saxon L, Steele E, Aspray T, et al. Randomised controlled trial of calcium and supplementation with cholecalciferol (vitamin D3) for prevention of fractures in primary care. BMJ. 2005;330:1003.

39. Lyons RA, Johansen A, Brophy S, Newcombe RG, Phillips CJ, Lervy B, et al. Preventing fractures among older people living in institutional care: a pragmatic randomised double blind placebo controlled trial of vitamin D supplementation. Osteoporos Int. 2007;18:811-8.

40. Gillespie WJ, Henry DA, O'Connell DL, Robertson J. Vitamin D, vitamin D analogues and calcium in prevention of fractures in involutional and postmenopausal osteoporosis. Cochrane Database Syst Rev. 1996;3:18.

41. Autier P, Gandini S. Vitamin D supplementation and Total mortality: a metaanalysis of randomized controlled trials. Arch Intern Med. 2007;167:1730-7.

42. Punthakee Z, Bosch J, Dagenais G, Diaz R, Holman R, Probstfield J, et al. Design, history and results of the thiazolidinedione intervention with vitamin $\mathrm{D}$ evaluation (TIDE) randomised controlled trial. Diabetologia. 2012;55:36-45.

43. Bolland MJ, Grey A, Gamble GD, Reid IR. Vitamin D supplementation and falls: a trial sequential meta-analysis. Lancet Diabetes Endocrinol. 2014;2:573-80.

44. Brooke $\mathrm{OG}$, Brown IR, Bone CD, et al. Vitamin D supplements in pregnant Asian women: effects on calcium status and fetal growth. Br Med J. 1980; 280(6216):751-54.

45. Pfeifer M, Begerow B, Minne HW, Abrams C, Nachtigall D, Hansen C. Effects of a short-term vitamin $D$ and calcium supplementation on body sway and secondary hyperparathyroidism in elderly women. J Bone Miner Res. 2000; 15(6):1113-18.

46. Chapuy MC, Pamphile R, Paris E, et al. Combined calcium and vitamin D3 supplementation in elderly women: confirmation of reversal of secondary hyperparathyroidism and hip fracture risk: the Decalyos II study. Osteoporos Int. 2002;13(3):257-64

47. Bischoff HA, Stahelin HB, Dick W, et al. Effects of vitamin D and calcium supplementation on falls: a randomized controlled trial. J Bone Miner Res. 2003;18(2):343-51.

48. Martineau AR, Timms PM, Bothamley GH, et al. High-dose vitamin D(3) during intensive-phase antimicrobial treatment of pulmonary tuberculosis: a double-blind randomised controlled trial. Lancet. 2011;377(9761):242-50.

49. Mosayebi G, Ghazavi A, Ghasami K, Jand Y, Kokhaei P. Therapeutic effect of vitamin D3 in multiple sclerosis patients. Immunol Invest. 2011;40(6):627-39.

50. Amestejani $M$, Salehi $B S$, Vasigh $M$, et al. Vitamin D supplementation in the treatment of atopic dermatitis: a clinical trial study. J Drugs Dermatol. 2012; 11(3):327-30.

51. Schreuder F, Bernsen RM, van der Wouden JC. Vitamin D supplementation for nonspecific musculoskeletal pain in non-Western immigrants: a randomized controlled trial. Ann Fam Med. 2012;10(6):547-55. 
52. Mozaffari-Khosravi H, Nabizade L, Yassini-Ardakani SM, Hadinedoushan $H$, Barzegar K. The effect of 2 different single injections of high dose of vitamin $\mathrm{D}$ on improving the depression in depressed patients with vitamin D deficiency: a randomized clinical trial. J Clin Psychopharmacol. 2013;33(3):378-85.

53. Hossain N, Kanani FH, Ramzan S, et al. Obstetric and neonatal outcomes of maternal vitamin D supplementation: results of an open-label, randomized controlled trial of antenatal vitamin D supplementation in Pakistani women. J Clin Endocrinol Metab. 2014;99(7):2448-55.

54. Bhan I, Dobens D, Tamez H, et al. Nutritional vitamin D supplementation in dialysis: a randomized trial. Clin J Am Soc Nephrol. 2015;10(4):611-19.

55. Jorde R, Sneve M, Figenschau Y, Svartberg J, Waterloo K. Effects of vitamin $D$ supplementation on symptoms of depression in overweight and obese subjects: randomized double blind trial. J Intern Med. 2008;264(6):599-609.

56. Wejse C, Gomes VF, Rabna P, et al. Vitamin D as supplementary treatment for tuberculosis: a double-blind, randomized, placebo-controlled trial. Am J Respir Crit Care Med. 2009;179(9):843-50.

57. Rastelli AL, Taylor ME, Gao F, et al. Vitamin D and aromatase inhibitor-induced musculoskeletal symptoms (AIMSS): a phase II, double-blind, placebocontrolled, randomized trial. Breast Cancer Res Treat. 2011;129(1):107-16.

58. Kjaergaard M, Waterloo K, Wang CE, et al. Effect of vitamin D supplement on depression scores in people with low levels of serum 25-hydroxyvitamin D: nested case-control study and randomised clinical trial. Br J Psychiatry. 2012;201(5):360-68.

59. Lehouck A, Mathieu C, Carremans C, et al. High doses of vitamin D to reduce exacerbations in chronic obstructive pulmonary disease: a randomized trial. Ann Intern Med. 2012;156(2):105-14.

60. Murdoch DR, Slow S, Chambers ST, et al. Effect of vitamin D3 supplementation on upper respiratory tract infections in healthy adults: the VIDARIS randomized controlled trial. JAMA. 2012;308(13):1333-39.

61. Abou-Raya A, Abou-Raya S, Helmii M. The effect of vitamin D supplementation on inflammatory and hemostatic markers and disease activity in patients with systemic lupus erythematosus: a randomized placebo-controlled trial. J Rheumatol. 2013;40(3):265-72.

62. McAlindon $T$, LaValley $M$, Schneider $E$, et al. Effect of vitamin $D$ supplementation on progression of knee pain and cartilage volume loss in patients with symptomatic osteoarthritis: a randomized controlled trial. JAMA. 2013;309(2):155-62.

63. Amrein $\mathrm{K}$, Schnedl $\mathrm{C}$, Holl A, et al. Effect of high-dose vitamin D3 on hospital length of stay in critically ill patients with vitamin D deficiency: the VITdAL-ICU randomized clinical trial. JAMA. 2014;312(15):1520-30.

64. Lopez-Torres Hidalgo J, Grupo A. [Effect of calcium and vitamin D in the reduction of falls in the elderly: a randomized trial versus placebo]. Med Clin (Barc). 2014;142(3):95-102.

65. Tran B, Armstrong BK, Ebeling PR, et al. Effect of vitamin D supplementation on antibiotic use: a randomized controlled trial. Am J Clin Nutr. 2014;99(1):156-61.

66. Turner AN, Carr Reese P, Fields KS, et al. A blinded, randomized controlled trial of high-dose vitamin $D$ supplementation to reduce recurrence of bacterial vaginosis. Am J Obstet Gynecol. 2014;211(5):479 e471-479 e413.

67. Martineau AR, MacLaughlin BD, Hooper RL, et al. Double-blind randomised placebo-controlled trial of bolus-dose vitamin D3 supplementation in adults with asthma (ViDiAs). Thorax. 2015;70(5):451-57.

68. Miskulin DC, Majchrzak K, Tighiouart H, et al. Ergocalciferol Supplementation in Hemodialysis Patients With Vitamin D Deficiency: A Randomized Clinical Trial. J Am Soc Nephrol. 2015.

69. Sandoughi M, Zakeri Z, Mirhosainee Z, Mohammadi M, Shahbakhsh S. The effect of vitamin D on nonspecific low back pain. Int J Rheum Dis. 2015;18(8):854-58.

70. Tukvadze N, Sanikidze E, Kipiani M, et al. High-dose vitamin D3 in adults with pulmonary tuberculosis: a double-blind randomized controlled trial. Am J Clin Nutr. 2015:102(5):1059-69.

71. Chapuy MC, Chapuy P, Meunier PJ. Calcium and vitamin D supplements: effects on calcium metabolism in elderly people. Am J Clin Nutr 1987:46:324-8.

72. Lips $P$, van Ginkel FC, Jongen MJ, Rubertus F, van der Vijgh WJ, Netelenbos JC. Determinants of vitamin D status in patients with hip fracture and in elderly control subjects. Am J Clin Nutr 1987:46:1005.

73. Lowik MR, Schrijver J, Odink J, van den Berg H, Wedel M, Hermus RJ. Nutrition and aging: nutritional status of "apparently healthy" elderly (Dutch nutrition surveillance system). J Am Coll Nutr 1990;9:18-27.

74. Lips P, Wiersinga A, van Ginkel FC, Jongen MJ, Netelenbos JC, Hackeng WH, Delmas PD, van der Vijgh WJ. The effect of vitamin D supplementation on vitamin D status and parathyroid function in elderly subjects. J Clin Endocrinol Metab 1988;67:644-50.
75. Mowe M, Bohmer T, Haug E. Vitamin D-mangel hos eldre sykehusinnlagte og hjemmeboende i Oslo. Tidsskr Nor Laegeforen 1998;118:3929-31.

76. Nes M, Lund-Larsen K, Trygg K, Hoivik HO, Pedersen Jl. Nutrition and the elderly in Europe: low prevalence of obesity and biochemical deficiencies in Norwegian subjects. Age Nutr 1993;4:72-81.

77. Finch S, Doyle W, Lowe C, Bates CJ, Prentice A, Smithers G, Clarke PC. National diet and nutrition survey: people aged 65 years and over. London: The Stationery Office; 1998.

78. Lund $\mathrm{B}$, Sorensen $\mathrm{OH}$. Measurement of 25 -hydroxyvitamin $\mathrm{D}$ in serum and its relation to sunshine, age and vitamin D intake in the Danish population. Scand J Clin Lab Invest 1979;39:23-30.

79. Schleicher RL, Sternberg MR, Lacher DA, Sempos CT, Looker AC, DurazoArvizu RA, Yetley EA, Chaudhary-Webb M, Maw KL, Pfeiffer CM, Johnson CL. The vitamin D status of the US population from 1988 to 2010 using standardized serum concentrations of 25-hydroxyvitamin D shows recent modest increases. Am J Clin Nutr 2016;104:454-61.

80. Gordon CM, DePeter KC, Feldman HA, Grace E, Emans SJ. Prevalence of vitamin D deficiency among healthy adolescents. Arch Pediatr Adolesc Med 2004;158:531-7.

81. Kauppi M, Impivaara O, Maki J, Heliovaara M, Marniemi J, Montonen J, Jula A. Vitamin D status and common risk factors for bone fragility as determinants of quantitative ultrasound variables in a nationally representative population sample. Bone 2009;45:119-24.

82. Pasco JA, Henry MJ, Nicholson GC, Sanders KM, Kotowicz MA. Vitamin D status of women in the Geelong Osteoporosis Study: association with diet and casual exposure to sunlight. Med J Aust 2001;175:401-5.

83. Javaid MK, Crozier SR, Harvey NC, Gale CR, Dennison EM, Boucher BJ, Arden NK, Godfrey KM, Cooper C, and the Princess Anne Hospital Study Group. Maternal vitamin D status during pregnancy and childhood bone mass at age 9 years: longitudinal study. Lancet 2006;367:36-43.

84. National Diet and Nutrition Survey. Results from years 1, 2, 3 and 4 (combined) of the Rolling Programme (2008/2009 - 2011/2012). London: Public Health London; 2014. Available from: https://www.gov.uk/ government/uploads/system/uploads/attachment_data/file/310995/NDNS_ Y1_to_4_UK_report.pdf.

85. Rockell JE, Skeaff CM, Williams SM, Green TJ. Serum 25-hydroxyvitamin D concentrations of New Zealanders aged 15 years and older. Osteoporosis Int 2006;17:1382-9.

86. Ministry of Health. 2012. Vitamin D status of New Zealand adults: Findings from the 2008/09 New Zealand adult nutrition survey. Wellington: Ministry of Health.

87. Tran B, Armstrong BK, Carlin JB, Ebeling PR, English DR, Kimlin MG, Rahman B, van der Pols JC, Venn A, Gebski V, Whiteman DC, Webb $P M$, Neale RE. Recruitment and results of a pilot trial of vitamin $D$ supplementation in the general population of Australia. J Clin Endocrinol Metab 2012;97:4473-80.

88. Waterhouse M, Tran B, Ebeling PR, English DR, Lucas RM, Venn AJ, Webb PM, Whiteman DC, Neale RE. Effect of vitamin D supplementation on selected inflammatory biomarkers in older adults: a secondary analysis of data from a randomised, placebo-controlled trial. Br J Nutr 2015;114:693-9.

89. Australian Health Survey 2011 - 2012 http://www.abs.gov.au/AUSSTATS/ abs@.nsf/DetailsPage/4364.0.55.0062011-12?OpenDocument.

90. Hurskainen AR, Virtanen JK, Tuomainen TP, Nurmi T, Voutilianen S. Association of serum 25-hydroxyvitamin D with type 2 diabetes and markers of insulin resistance in a general older population in Finland. Diabetes/Metab Research Reviews 2012;28:418-23

91. Salminen M, Saaristo P, Salonoja M, Vaapio S, Vahlberg T, Lamberg-Allardt C, Aarnio P, Kivela S-L. Arch Gerontol Geriatric 2015;61:419-24.

92. Carlberg C, Seuter S, de Mello VD, Schwab U, Voutilainen S, Pulkki K, Nurmi T, Virtanen J, Tuomainen TP, Uusitupa M. Primary Vitamin D Target Genes Allow a Categorization of Possible Benefits of Vitamin D3 Supplementation. PLOS ONE. 2013;8(7): e71042.

93. Hirani V, Primatesta P. Vitamin D concentrations among people aged 65 years and over living in private households and institutions in England: population survey. Age Ageing. 2005;34:485-91.

94. Looker AC, Dawson-Hughes B, Calvo MS, Gunter EW, Sahyoun NR. Serum 25-hydroxyvitamin D status of adolescents and adults in two seasonal subpopulations from NHANES III. Bone 2002;30:771-77. 